Original Articles

Juntendo Medical Journal 2015. 61 (1), 29-33

\title{
Association between Radiographic Severity of Osteoarthritis of Finger Joints and Bone Mineral Density
}

\author{
YOSHIYUKI IWASE*1), YUKIO SHIMURA*1), MAMIKO SAWA*1), \\ HIDETOSHI NOJIRI*1), YUJI MAKINO*1), MASARU TSUCHIYA*1), \\ KENTARO ARITOMI*2), KAZUO KANEKO*2), HiSASHI KUROSAWA*1) \\ *1) Department of Orthopaedic Surgery, Juntendo Tokyo Koto Geriatric Medical Center, Tokyo, Japan, *2) Department of \\ Orthopaedic Surgery, Juntendo University Faculty of Medicine, Tokyo, Japan
}

Objective: To determine whether or not there is a correlation between the severity of hand osteoarthritis (OA) and low bone mineral density (BMD).

Materials: In 30 patients with hand OA who attended our department with chief complaint of arthralgia in the fingers, data on BMD and the radiographic severity of hand OA were statistically analyzed. Of the 30 subjects studied, 24 were females and 6 males. All subjects aged between 49 and 85 years (mean: 70.0 years). They consisted of 18 subjects with Heberden's nodes, 8 with Bouchard's nodes, and 9 with rhizarthrosis.

Methods: Radiographic severity of hand OA was scored with the Kellgren/Lawrence scale (grade 0-4). BMD of vertebral bodies was measured by dual-energy X-ray absorptiometry.

Results: A statistically significant correlation was found between the radiographic severity of Heberden's nodes and low BMD, whereas neither rhizarthrosis nor Bouchard's nodes showed any correlation between radiographic severity and BMD.

Conclusions: A statistically significant correlation between the radiographic severity of hand OA and BMD was established solely for Heberden's nodes. Although low BMD may influence the progression of hand OA, there may also be other influencing factors.

Key words: hand osteoarthritis, bone mineral density, Heberden's nodes, Bouchard's nodes, rhizarthrosis

\section{Introduction}

Heberden's nodes, Bouchard's nodes, and rhizarthrosis are well known features of osteoarthritis $(\mathrm{OA})$, which is linked to aging and, when occurring in hands, associated with finger pain and dysfunction ${ }^{1,2)}$. Reported risk factors for hand $\mathrm{OA}$ include increasing age over 50 , female sex, obesity, mechanical forces, and family history ${ }^{1}$. OA, a disease of the locomotor system that tends to increase in prevalence with aging and to worsen every year after onset, serves as a predisposing factor for fractures, causing every kind of locomotor dysfunction ${ }^{3,4)}$. Furthermore, female sex is a well- known risk factor for osteoporosis. Thus, osteoporosis and hand OA have common factors. Nevertheless, whether the disease osteoporosis is closely linked with the onset of hand OA is not clear because there are two opposing theses on this theme. In addition, it also remains to be established whether there is a correlation between the progression of hand OA and severity of osteoporosis. The present study was conducted to determine whether or not there is an association between the severity of hand $\mathrm{OA}$ and low bone mineral density (BMD).

\section{Materials and methods}

The subjects of this study were 30 patients with

Corresponding author: Yoshiyuki Iwase

Department of Orthopaedic Surgery, Juntendo Tokyo Koto Geriatric Medical Center

3-3-20 Shinsuna, Koto-ku, Tokyo 136-0076, Japan

TEL: +81-3-5632-3111 FAX: +81-3-5632-3728 E-mail: iwase@juntendo.gmc.ac.jp

[Received Sep. 25, 2014] [Accepted Nov. 10, 2014] 
Table-1 Background characteristics of subjects

\begin{tabular}{lll}
\hline Height $(\mathrm{cm})$ & $142-185$ & (mean: 157.4) \\
Body weight $(\mathrm{kg})$ & $33.5-84$ & (mean: 54.6) \\
BMI $\left(\mathrm{kg} / \mathrm{m}^{2}\right)$ & $13.3-29.9$ & (mean: 21.9) \\
BMD $\left(\mathrm{g} / \mathrm{cm}^{2}\right)$ & $0.81-1.42$ & (mean: 1.00) \\
VAS $(\mathrm{mm})$ & $3-84$ & (mean: 44.8) \\
Grip strength (kg) Left & $2-26$ & (mean: 14.6) \\
& $5-39$ & (mean: 16.1) \\
Dominant hand (number of subjects) & Left, 3; right, 27 & \\
Occupation (number of subjects) & Unemployed, 26 & \\
& Employed, 4 (sushi chef, 1; owner of \\
& buckwheat-noodle shop, 1; barber, 1; clerk, 1) \\
\hline
\end{tabular}

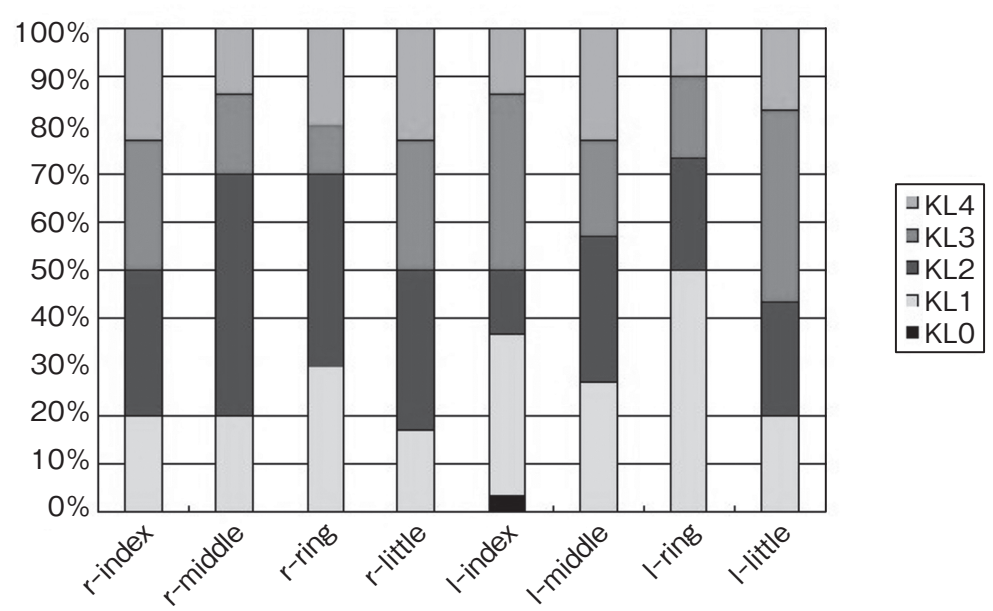

Figure-1 Distribution of K/L grades in subjects with Heberden's nodes

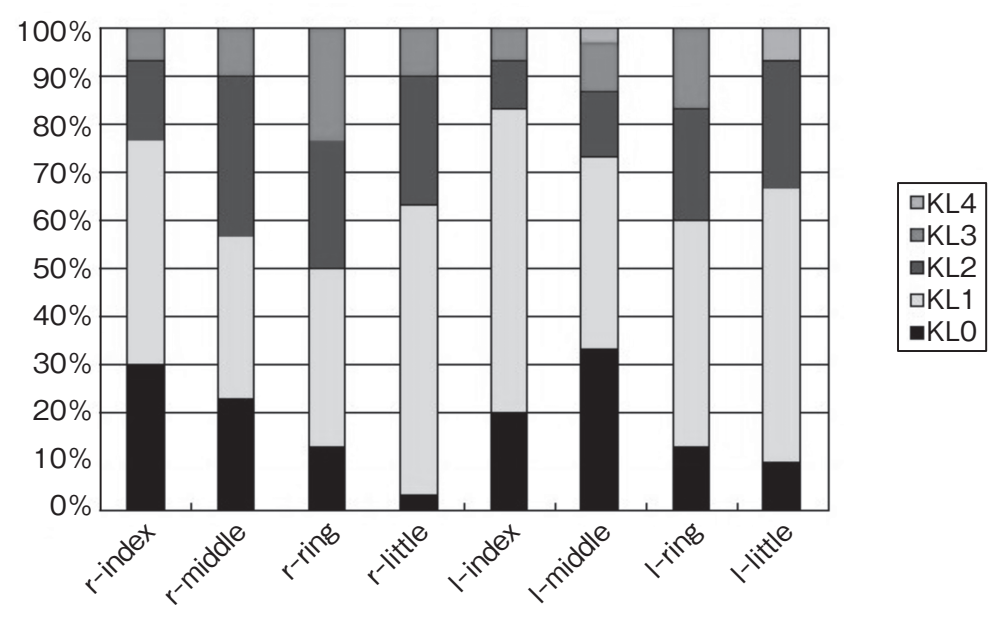

Figure-2 Distribution of K/L grades in subjects with Bouchard's nodes

hand OA who attended our department between April and December 2013 with chief complaint of arthralgia in the fingers. Of these subjects, 24 were females and 6 males. Their ages ranged from 49 to
85 years, with a mean of 70.0 years. Table -1 shows their background characteristics. The subjects consisted of 18 with Heberden's nodes, 8 with Bouchard's nodes, and 9 with rhizarthrosis. Of the 


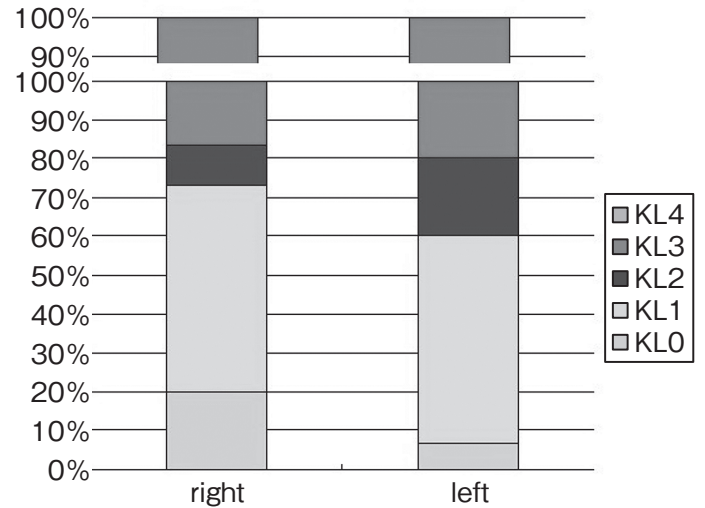

Figure-3 Distribution of $\mathrm{K} / \mathrm{L}$ grades in subjects with rhizarthrosis

Table-2 Correlation between radiographic severity (mean) scored with K/L scale and BMD (adjusted for age and BMI)

\begin{tabular}{lcc}
\hline & Correlation, $r$ & $\begin{array}{l}\text { Significance } \\
\text { probability, } P\end{array}$ \\
\hline $\begin{array}{l}\text { BMD: Heberden's nodes scored } \\
\text { with K/L scale }\end{array}$ & -0.38 & 0.048 \\
$\begin{array}{l}\text { BMD: Bouchard's nodes scored } \\
\text { with K/L scale }\end{array}$ & -0.05 & 0.809 \\
$\begin{array}{l}\text { BMD: rhizarthrosis scored } \\
\text { with K/L scale }\end{array}$ & 0.09 & 0.658 \\
\hline
\end{tabular}

$(\mathrm{p}<0.05)$

Table-3 Correlation between radiographic severity (mean) scored with K/L scale and VAS or grip strength

\begin{tabular}{lcc}
\hline & Correlation, $r$ & $\begin{array}{l}\text { Significance } \\
\text { probability, } P\end{array}$ \\
\hline $\begin{array}{l}\text { VAS value: Heberden's nodes } \\
\text { scored with K/L scale }\end{array}$ & 0.18 & 0.356 \\
$\begin{array}{l}\text { VAS value: Bouchard's nodes } \\
\text { scored with K/L scale }\end{array}$ & 0.07 & 0.729 \\
$\begin{array}{l}\text { VAS value: rhizarthrosis } \\
\text { scored with K/L scale }\end{array}$ & -0.18 & 0.354 \\
$\begin{array}{l}\text { Grip strength: Heberden's nodes } \\
\text { scored with K/L scale }\end{array}$ & -0.18 & 0.353 \\
$\begin{array}{l}\text { Grip strength: Bouchard's nodes } \\
\text { scored with K/L scale }\end{array}$ & 0.12 & 0.543 \\
$\begin{array}{c}\text { Grip strength: rhizarthrosis } \\
\text { scored with K/L scale }\end{array}$ & 0.13 & 0.523 \\
\hline
\end{tabular}

$(\mathrm{p}<0.05)$

total, 2 with rhizarthrosis underwent arthrodesis and the others received conservative therapy such as orthotic therapy. The duration of pain ranged from several weeks to 10 years, with a mean of 17.4 months. The radiographic severity of hand OA was scored with the Kellgren/Lawrence (K/L) scale (grade $0-4)^{5)}$. BMD of vertebral bodies was measured by dual-energy X-ray absorptiometry
(DEXA) to evaluate total-body BMD. Furthermore, grip strength and pain were graded with a visual analogue scale (VAS), and their correlation with the severity of hand OA was evaluated. The mean K/L grade for hand OA, BMD adjusted age, and body mass index (BMI) were statistically analyzed with Spearman's rank correlation coefficient. The level of statistical significance was set at $\mathrm{p}<0.05$.

\section{Results}

Figure- 1 shows the distribution of $\mathrm{K} / \mathrm{L}$ grades for Heberden's nodes. As is apparent from this graph, $\mathrm{K} / \mathrm{L}$ grade ranged from 0 to 4 , and a grade of 2 tended to predominate in this form of hand $\mathrm{OA}$ (Figure-1). For Bouchard's nodes, K/L grade showed the following distribution: grades 0 and $1-\mathrm{i}$. e., less severe OA-accounted for about $70-80 \%$ of the total, and few subjects had grades 3 and 4 -more severe OA (Figure-2). The same was almost true in the case of rhizarthrosis, i.e., grades of 0 and 1 accounted for about $60-70 \%$ of the total, and few subjects had grades 3 and 4 (Figure- 3 ).

According to the results of our statistical analyses, $\mathrm{K} / \mathrm{L}$ grading and BMD data showed that the severity of Heberden's nodes tended to increase with a decrease in BMD, with significance of $p<$ 0.05 (Table-2). Other joints showed no correlation between the severity scored with the K/L scale and BMD. VAS showed no correlation with BMD regardless of the joint studied. Grip strength also showed no correlation with $\mathrm{K} / \mathrm{L}$ grade regardless of the joint studied (Table-3).

Cases are presented below.

\section{Discussion}

The results of our study revealed a distinct positive correlation between low lumbar BMD and the radiographically demonstrated degree of progression of Heberden's nodes. This finding indicates that low BMD also plays a small part in the exacerbation of $\mathrm{OA}$, although other unknown contributing factors are considered to be highly responsible for such exacerbation. In contrast, there was no correlation between low lumbar BMD and the progression of rhizarthrosis or Bouchard's nodes. This finding indicates that, whereas other unknown contributing factors are highly responsible for exacerbation of these forms of hand OA, low 
BMD is not very responsible. As has been described, low BMD was associated with exacerbation of Heberden's nodes, but not the progression of Bouchard's nodes or rhizarthrosis. With respect to this finding, attention should be given to the fact that, in general, Heberden's nodes have a significantly higher prevalence than the other two forms of OA. No further details about this are clear, however.

In 2008, Tsuchiya et al. determined the prevalence of hand $\mathrm{OA}$ in 35 patients at the initial and follow-up assessments to detect a change in BMD. Assessment of hand OA was carried out in frontal plain X-rays of the left hand used for BMD measurement (made in accordance with the DXR imaging protocol [DIP]). Patients with $\mathrm{K} / \mathrm{L}$ grade of 2 or higher were regarded as having hand OA. The 35 patients were classified according to prevalence of hand OA into two groups-increased and unchanged-and an intergroup difference in the change in BMD was then examined. They reported that no correlation with BMD was found ${ }^{6)}$. On the other hand, in 2006, Zoli reported that postmenopausal women with erosive osteoarthritis (EOA) of the hand had a significantly higher prevalence of osteoporosis of the lumbar spine compared with postmenopausal women without hand EOA and controls ${ }^{7)}$. According to Zoli's findings, the onset of osteoporosis of the lumbar spine was correlated with that of hand OA. Furthermore, the results of our present study newly suggested a correlation between the progression of osteoporosis of the lumbar spine and that of some forms of hand OA. Nevertheless, there are reports of opposing findings. No definite conclusion has therefore been reached concerning the correlation between the progression of hand $\mathrm{OA}$ and low $\mathrm{BMD}$, regardless of its onset or progression.

In regard to osteoporosis and $\mathrm{OA}$ of the knee joint as a weight-bearing joint, the following two findings have been reported regarding their onset and progression. In 2004, Isbagio reported that there were no significant difference in total bone mineral content between subgroups of knee OA grades ${ }^{8}$. On the other hand, in 2014, Im reported that low BMD of the lumbar spine was associated with a lower incidence of knee $\mathrm{OA}^{9}$. These views are not in accord. There is no report that low BMD is associated with exacerbation of OA, however.
What is the major cause of exacerbation and progression of hand OA? One of the possibilities is considered to lie in the repetitive involvement of minute injuries of the articular cartilage. In 1989, Bergenudd reported that women with Heberden's nodes had more physically demanding jobs ${ }^{10)}$. Clinical studies of the knee (as a weight bearing joint) show that, whereas a higher incidence of knee OA is observed in an exercise environment in which sudden acceleration, quick stops, and abrupt changes of direction are required, as in soccer ${ }^{11}$, no increase in the incidence of $\mathrm{OA}$ is seen in any environment in which joints are exposed to monotonous repetitive axial loading, as in a longdistance race runner ${ }^{12}$. These findings suggest the notion that repetitive application of injurious forces to articular surfaces may cause repeated minute cartilage injuries, thereby eventually leading to OA.

From the viewpoint of treatment, on the other hand, the association between knee OA and BMD has been reported by Alekseeva in 2013 as follows: therapy with ibandronic acid, a drug for treatment of osteoporosis, resulted in a significant reduction in pain, knee joint stiffness, and locomotor functional failure in patients with gonoarthrosis ${ }^{13)}$. If any drug for treatment of osteoporosis is effective in producing an improvement in symptoms, it may hold promise for the symptomatic improvement of hand $\mathrm{OA}$ as well.

In any case, further studies in a greater number of subjects through various approaches may be needed to clarify the mechanism of hand OA progression, as well as to establish the correlation between progressive worsening of hand $\mathrm{OA}$ and exacerbation of osteoporosis. Low BMD has been known to lower the quality of the subchondral bone ${ }^{14)}$. Therefore, an OA drug that provides evidence to show usefulness in improving the quality of the subchondral bone is expected to become available in the future and applicable in the treatment of OA.

\section{Acknowledgements}

The authors declare no conflict of interest.

A summary of this paper was presented at the 57th Annual Meeting of the Japanese Society for Surgery of the Hand 2014 (Okinawa). 


\section{References}

1) Kloppenburg M, Kwok WY: Hand osteoarthritis-a heterogeneous disorder. Nat Rev Rheumatorol, 2011; 8: 22-31.

2) Jones G, Cooley HM, Bellamy N: A cross-sectional study of the association between Heberden's nodes, radiographic osteoarthritis of the hands, grip strength, disability and pain. Osteoarthritis Cartilage, 2001; 9: 606611.

3) Hagino H: Locomotive syndrome and frailty. Osteoprosis as an underlying disorder in the locomotive syndrome. Clin Calcium, 2012; 22: 41-48.

4) Stone KL, Seeley DG, Lui LY, et al: BMD at multiple sites and risk of fracture of multipletypes: long-term results from the Study of Osteoporotic Fractures. J Bone Miner Res, 2003; 18: 1947-1954.

5) Kellgren JH, Lawrence JS: Radiological assessment of osteo-arthrosis. Ann Rheum Dis, 1957; 16: 494-502.

6) Tsuchiya T, Takeuchi Y, Toba N: Association between osteoarthritis of the interphalangeal joint and bone mineral density as assessed over time. Orthoped Traumatol, 2008; 57 Suppl 1: 180.

7) Zoli A, Lizzio MM, Capuano A, Massafra U, Barini A, Ferraccioli G: Osteoporosis and bone metabolism in postmenopausal women with osteoarthritis of the hand.
Menopause, 2006; 13: 462-466.

8) Isbagio H: Factors affecting radiographic progression of knee osteoarthritis. Acta Med Indones, 2004; 36: 87-92.

9) Im Gl, Kim MK: The relationship between osteoarthritis and osteoporosis. J Bone Miner Metab, 2014; 32: 101109.

10) Bergenudd H, Lindgrade F, Nilsson B: Prevalence and coincidence of degenerative changes of the hands and feet in middle age and their relationship to occupational work load, intelligence, and social background. Clin Orthop Relat Res, 1989; Feb (239) : 306-310.

11) Klunder KB, Rud B, Hansen J: Osteoarthritis of the hip and knee joint in retired football players. Acta Orthop Scand, 1980; 51: 925-927.

12) Lane NE, Bloch DA, Jones HH, Marshall WH Jr, Wood PD, Fries JF: Long-distance running, bone density, and osteoarthritis. JAMA, 1986; 255: 1147-1151.

13) Alekseeva LI, Zaitseva EM, Sharapova EP, et al: Evaluation of the efficacy and tolerance of ibandronic acid in patients with osteoarthrosis in the knee joints concurrent with osteoporosis: a pilot study. Ter Arkh, 2013; 85: 30-36.

14) Akamatsu Y, Mitsui N, Hayashi T, Kobayashi H, Saito T: Low bone mineral density is associated with the onset of spontaneous osteonecrosis of the knee. Acta Orthop, 2012; 83: 249-255. 